\title{
A RECONFIGURAÇÃO DA POLÍTICA BOLIVIANA: RECONSTITUIÇÃO DE UM CICLO DE CRISES ${ }^{1}$
}

\author{
Rafaela N. Pannain \\ é pesquisadora de pós-doutorado do Centro Brasileiro de Análise e Planejamento (Cebrap). \\ São Paulo, SP, Brasil.E-mail: <rafaelapannain@hotmail.com>
}

Orcid: 0000-0002-4782-0896

http://dx.doi.org/10.1590/0102-287313/105

\section{Introdução}

A possibilidade de reestruturação da ordem estatal para a participação dos indígenas na Bolívia se deu a partir da mobilização de organizações indígenas e camponesas. Embora a transição para o regime democrático tenha ocorrido no final da década de 1970 e no início da seguinte, é possível dizer que ela não se completou até a primeira década do século XXI, quando representantes dos setores subalternos tiveram pela primeira vez a oportunidade de participar de posições importantes no Estado.

A vitória de Evo Morales, em 2005, a elaboração de uma nova constituição política, entre 2006 e 2008, e as eleições dos membros do Poder Legislativo, em 2005 e 2009, marcaram a inclusão de parte da população indígena boliviana no

\footnotetext{
1 Este artigo apresenta parte da reconstituição do processo crítico boliviano analisado em minha tese de doutorado (Pannain, 2014), que contou com o financiamento da Fundação de Amparo à Pesquisa do Estado de São Paulo (Fapesp), processo nº 10/17678-1, e da Coordenação de Aperfeiçoamento de Pessoal de Nível Superior (Capes). Agradeço a Brasílio Sallum Júnior pela orientação desta pesquisa, a Débora Alves Maciel, Caio Vasconcellos e pareceristas anônimos(as) pelos comentários e sugestões a este artigo.
} 
campo político institucional nacional. Tal mudança resultou de uma grave crise política desencadeada por uma forte mobilização social entre os anos de 2000 e 2005, de setores que se encontravam praticamente excluídos da política institucional do país. A mobilização de setores subalternos, principalmente indígenas e camponeses, rompeu as fronteiras do campo político institucional.

Este artigo apresenta a dinâmica do processo político pelo qual as organizações indígenas e camponesas romperam as fronteiras desse campo, aumentando seu espaço de atuação. A reconstrução do ciclo de crises políticas apresentada acompanha três organizações sociais centrais nas mobilizações populares: a Confederación Sindical Única de Trabajadores Campesinos de Bolivia (CSUTCB), a Confederación de los Pueblos Indígenas de Bolivia (Cidob) e o Consejo de Ayllus y Markas del Qullasuyu (Conamaq) ${ }^{2}$. A análise da atuação dessas organizações, nos diferentes momentos do ciclo de cri288 ses políticas, faz-se necessária para o entendimento de suas diferenças e da importância de suas alianças, bem como da recomposição do campo uma vez superada a crise.

\section{A análise da crise política como método}

Encontramos, na literatura, explicações estruturais e conjunturais para a crise política estudada. Algumas destacam a persistência de um colonialismo interno na Bolívia, corroborando a interpretação de Silvia Rivera Cusicanqui (1983) sobre a incapacidade da Revolução Nacional de 1952 em acabar com o padrão de organização social construído

\footnotetext{
2 A CSUTCB, diferentemente das outras duas organizações, se formou em 1979 reivindicando a dupla identidade de seus membros: camponesa e indígena. Apesar da ênfase na identidade indígena no momento de sua formação e da importância que essa tomou em diferentes momentos da história da organização, no cenário político boliviano atual ela é mais identificada por sua identidade camponesa. Por essa razão, ao longo deste artigo, refiro-me à CSUTCB como uma organização camponesa. Para uma análise detalhada da formação dessas organizações, bem como dos principais movimentos sociais bolivianos, cf. García Linera. (2008b).
} 
durante a colônia, apesar de seu discurso homogeneizante e suas pretensões antioligárquicas (cf. Dunkerley, 2007; García Linera, 2008a; Hylton e Thomson, 2005; Tapia, 2007). Outras apontam causas relacionadas às estruturas políticas de "curta duração", especialmente referentes ao modelo neoliberal de configuração estatal e às crises de legitimidade dos partidos políticos e do modelo de aliança reeditado desde 1985 (cf. Calderón Gutiérrez e Gamarra, 2004; Chávez e Mokrani, 2007; Mamani Ramírez, 2007; García Linera, 2008a; Mayorga, 2009; Tapia, 2005).

Embora essas análises apontem importantes justificativas para o desencadeamento das mobilizações populares, elas não permitem compreender como setores subalternos rompem as fronteiras do campo político institucional e sua reorganização uma vez superada a crise. Diferentemente das análises que explicam o último ciclo de crises políticas na Bolívia a partir de suas causas, proponho um estudo da dinâmica dessas crises. Segundo Michel Dobry (1992), quando nos concentramos nas causas e consequências das crises, negligenciamos o que é fundamental para sua compreensão: a dinâmica das lutas entre os atores. Haveria, assim, uma possível autonomia entre causas e processos de crise que essas análises não levariam em conta.

Partindo da perspectiva proposta por Dobry, atentamos para a fluidez do sistema social em momentos críticos, observada a partir da mudança na configuração interna e externa dos setores sociais. O autor trata de sistemas sociais complexos, caracterizados pela autonomia relativa de seus setores dotados de lógicas sociais, temporalidades, culturas, vocabulários específicos e historicamente construídos. As lógicas setoriais definem os cálculos pertinentes para os atores. Há, dessa forma, uma racionalidade socialmente estruturada, restrita pelas lógicas setoriais.

A fluidez das estruturas sociais em momentos críticos é caracterizada por uma redução da autonomia dos setores. 
Durante graves crises políticas, há uma ruptura nas rotinas, nas temporalidades do setor da política institucional, e os cálculos realizados pelos atores deixam então de ser guiados especialmente pelas lógicas próprias de cada setor, gerando imprevisibilidade. Com a redução da autonomia do setor da política institucional, suas fronteiras passam a ser permeáveis à atuação de atores de outros setores. Dessa forma, as grandes crises políticas correspondem a mobilizações multissetoriais,

A fluidez do sistema social nos momentos de crise, formulada teoricamente por Dobry, foi igualmente observada por René Zavaleta Mercado (1983) ao estudar importantes mobilizações sociais ocorridas na Bolívia em novembro de 1979. O autor argumenta que, na Bolívia, a união entre as classes camponesa e operária foi possível apenas durante uma grave crise política, a qual teria criado uma intersubjetividade, ou seja, uma lógica comum a grupos que teriam lógicas tão distintas em conjunturas ordinárias. Segundo 290 ele, as graves crises políticas seriam situações privilegiadas para o conhecimento da sociedade boliviana, em função da sua formação social abigarrada (heterogênea, bagunçada). Este conceito faz referência ao processo desigual de desenvolvimento do capitalismo na Bolívia, que não foi capaz de produzir em todo o território nacional "um processo de acumulação originária, no sentido de concentração da terra, concentração dos meios de produção e destruição de estruturas sociais e formas de vida preexistentes" (Tapia, 2010, p. 100). Para Zavaleta Mercado, grandes crises políticas são então acontecimentos nacionalizadores, por criar entre os diferentes setores sociais a possibilidade de um tempo comum, inexistente em conjunturas ordinárias.

$* * *$

A eleição de Evo Morales à Presidência da Bolívia foi precedida pelo ciclo de mobilizações populares iniciado 
com a "guerra da água" e mobilizações do campesinato. A primeira fase da crise chegaria ao fim com a queda do presidente Carlos Mesa, em 2005. Embora a instabilidade política persista após 2006, quando o Movimiento al Socialismo (MAS), partido de Evo Morales, assume o controle do governo nacional, a crise política entra em uma nova fase. São as características distintas dos dois períodos deste processo de crise que nos permitem identificar duas fases do mesmo ciclo crítico. Para fins de análise, apresento aqui a primeira fase dividida em três diferentes momentos: a ascensão da mobilização, sua expansão e seu ápice.

\section{A mobilização camponesa e a luta pela água: a "democracia pactuada" entra em crise}

Acordos entre lideranças de grandes partidos políticos e de partidos menores foram característicos da política institucional boliviana entre 1985-2003, período conhecido como “democracia pactuada". Por duas décadas, esse sistema garantiu a alternância dos principais partidos no comando dos poderes Executivo e Legislativo ${ }^{4}$. Durante esse período, alcançou-se uma estabilidade institucional cujo alicerce foram a ausência de disputa entre projetos políticos significativamente distintos e a impossibilidade de influência de representantes da maioria indígena na política institucional em nível nacional. Embora um intelectual aymara tenha sido eleito vice-presidente em 1994 e deputados indígenas ocupassem algumas cadeiras no Congresso Nacional, suas posições ainda eram periféricas no campo (Urquidi, 2007, p. 180).

\footnotetext{
3 Para os diferentes pactos entre os partidos políticos no período de 1984 a 2001, cf. Calderón Gutiérrez e Gamarra (2004, p. 7).

${ }^{4}$ De acordo com a Constituição Política boliviana vigente naquele período, caso nenhum candidato à presidência recebesse uma votação superior a $50 \%$ dos votos válidos, cabia ao Congresso escolher o presidente a partir de uma lista com os três primeiros colocados. Esse foi um mecanismo determinante no funcionamento do sistema político boliviano pois, até a década de 2000, nenhum candidato conseguiu a maioria dos votos dos bolivianos.
} 
O fato de todos os governos durante a democracia pactuada terem declarado estado de sítio comprova que esse acordo entre elites era contestado por parte da sociedade boliviana (Pannain, 2014, p. 88); contudo, apenas em 2000 a contestação desencadearia um ciclo de crises políticas. Naquele ano, as mobilizações em torno do direito à água marcaram o início do fim da democracia pactuada e uma nova fase de fortalecimento das organizações camponesas e indígenas. A revolta popular em Cochabamba, conhecida como "guerra da água", a insurreição articulada pela CSUTCB no Altiplano de La Paz e a mobilização dos plantadores de folha de coca evidenciaram a desarticulação entre o poder político e a sociedade. Nos três casos, o campesinato indígena foi um ator central na mobilização social ${ }^{5}$.

A primeira foi desencadeada pela transferência do serviço de água e esgoto da cidade de Cochabamba a uma empresa privada e pela promulgação da Lei de Água Potável 292 e Esgoto Sanitário, em 1999. Além do grande aumento nas tarifas de água dos moradores de Cochabamba, essas mudanças desarticulariam os sistemas de captação e distribuição de água autônomos desenvolvidos por aqueles que viviam no campo e em bairros periféricos da cidade. Criada em novembro de 1999, a Coordenadoria de Defesa da Água e da Vida foi o resultado de uma articulação entre diferentes setores da sociedade, notadamente camponeses dos Vales de Cochabamba e operários urbanos. Bloqueios foram organizados nas estradas e principais avenidas da cidade. Apesar da resposta violenta inicial do governo, este se viu, com o crescimento da mobilização social, obrigado a modificar a contestada lei e devolver ao controle municipal a empresa de água de Cochabamba, agora em coordenação com representantes indicados pela Coordenadoria.

\footnotetext{
${ }^{5}$ Para uma revisão do que chamo de primeira fase do ciclo de crises políticas, cf. García Linera et al. (2008), Gutierrez Aguilar (2008) e Hylton e Thomson (2005).
} 
Em abril de 2000, enquanto em Cochabamba ainda se viam os enfrentamentos em torno da privatização da água, camponeses iniciaram bloqueios em estradas dos departamentos de La Paz, Cochabamba, Oruro, Chuquisaca e Tarija contra a Lei de Águas. A atuação da CSUTCB e de seu secretário geral, Felipe Quispe, foi fundamental na mobilização. A retórica de Quispe evocava as lembranças do cerco de La Paz pelo líder indígena Tupac Katari no século XVIII e do exército indígena liderado no século seguinte por Zárate Willka. Destacou-se a insurreição organizada no departamento de La Paz, onde os protestos haviam sido fortemente reprimidos pelo governo, servindo de estopim para o incêndio de instalações do Estado boliviano por parte dos insurgentes.

Concomitantemente à mobilização camponesa organizada pela CSUTCB no Altiplano, outro importante setor do campesinato, os cocaleiros, levantou-se contra o governo central na região do Chapare cochabambino. Tratava-se de uma resposta à violência estatal - desencadeada pela política de eliminação da produção da folha de coca - e à ameaça ao sistema tradicional de uso da água. As disputas pelo controle da CSUTCB entre Felipe Quispe e Evo Morales, presidente das Seis Federações do Trópico Cochabambino, levaram à criação de dois diretórios paralelos da CSUTCB. Apesar dessas divergências, Quispe apoiaria o movimento cocaleiro quando este foi fortemente reprimido pelo governo.

Paralelamente às mobilizações nas ruas e estradas, tanto o movimento cocaleiro quanto o setor do campesinato representado por Quispe adotaram uma estratégia de participação no campo político institucional com a criação de partidos políticos. O Movimiento al Socialismo - Instrumento Político por la Soberanía de los Pueblos (MAS-IPSP) - vertente do instrumento político surgido como Asamblea para la Soberanía de los Pueblos, em 1995, a partir do encontro de organizações camponesas e indígenas - teria como principal representante Evo Morales (Stefanoni, 2002). Já Quispe fundaria em 2000 o Movimiento Indigena Pachakuti (MIP). 


\section{Os indígenas das terras baixas entram em cena: a expansão da mobilização}

Ainda em 2002, povos indígenas das terras baixas e altas organizaram a "Marcha pela Soberania Popular, pelo

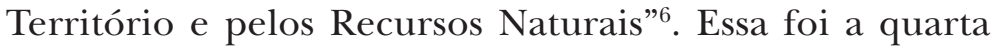
marcha organizada pelos indígenas das terras baixas desde a famosa "Marcha pelo Território e Dignidade" de 1990. Todas até então levavam em seu nome a defesa do território, principal reivindicação desses indígenas nas últimas décadas. Contudo, na marcha de 2002, pela primeira vez falava-se em "soberania popular". Os indígenas mobilizados não apenas reivindicavam que o Estado reconhecesse seus direitos, mas exigiam a participação no Estado e em sua redefinição, denunciando o projeto de lei que limitaria a participação da maioria dos bolivianos nos debates em torno da nova constituição. Exigia-se a convocação de uma assembleia constituinte na qual a participação dos diferentes 294 setores sociais não estivesse necessariamente mediada pelos partidos políticos.

Teceu-se uma importante aliança entre representantes de setores subalternos a partir do encontro entre os indígenas das terras baixas que haviam iniciado a IV Marcha, organizados em torno do Bloco Oriente, indígenas das terras altas, representados pelo Conamaq, e organizações de camponeses e indígenas da Amazônia. Contudo, a dificuldade de articulação dos setores subalternos ficou evidente na ausência dos cocaleiros e na atuação de dirigentes da confederação de povos indígenas das terras baixas, a Cidob, com quem o governo negociou paralelamente um acordo com o intuito de desmobilizar a marcha. Este acordo foi rejeitado pelos organizadores da marcha e por autoridades do Conamaq. Fracassada a tentativa de esvaziar a mobilização, ${ }^{6}$ Para informações sobre a Marcha e seus preparativos, cf. o livro de Romero Bonifaz
(2005), que participou da mobilização como assessor das organizações indígenas. 
o governo se viu obrigado a assinar um novo acordo nacional pela Assembleia Constituinte com os representantes das organizações que haviam caminhado centenas de quilômetros até La Paz.

\section{0 fim da democracia pactuada: a crise atinge seu ápice}

As eleições para presidente, deputados e senadores, em junho de 2002, ocorreram em um contexto de crescente mobilização social e seguidas derrotas dos governos nacionais. Nelas, o MAS-IPSP, representante do movimento cocaleiro, expandiu seu alcance para diferentes departamentos do país e obteve o segundo lugar nas eleições presidenciais, com a candidatura de Evo Morales. Contudo, ainda que o modelo econômico e político ao qual estava associado o ex-presidente Gonzalo Sánchez de Lozada, o "Goni”, já demonstrasse importantes sinais de crise, este foi eleito presidente com 22,46\% dos votos. O grande percentual de votos de Evo Morales (20,94\%) e de Manfred Reyes (20,91\%), dois relativos outsiders, indica um enfraquecimento dos partidos que ocupavam as posições centrais no campo político institucional. Coube mais uma vez ao Parlamento escolher o presidente dentre os primeiros candidatos, reeditando um acordo político entre partidos, típico da "democracia pactuada".

No ano seguinte à eleição de Goni, a crise política atingiria seu ápice. Após o anúncio de um novo imposto sobre os salários, a Central Obrera Boliviana e Evo Morales convocaram a população a se rebelar contra a medida. A polícia nacional, igualmente afetada pelo novo imposto, juntou-se à mobilização, entrando em confronto com o exército. Os enfrentamentos deixaram um saldo de 15 mortos, entre policiais e militares, explicitando de forma incontestável a gravidade da crise. Em La Paz, os escritórios dos principais partidos da "democracia pactuada" e edifícios governamentais foram queimados. Nos confrontos de fevereiro, 34 pessoas foram mortas. 
Em setembro, a CSUTCB comandada por Felipe Quispe organizou uma marcha em direção à sede do governo. Após forte repressão, Quispe iniciou uma greve de fome com outras duas mil pessoas, e bloqueios de estradas foram organizados em diversas províncias do Altiplano. Em diferentes províncias do departamento de La Paz, autoridades estatais foram expulsas e substituídas por autoridades sindicais ou comunais. Felipe Quispe explica os eventos daquele ano:

A bandeira tricolor [boliviana] já não servia. Os monumentos tinham que ser destruídos. Destruímos alguns monumentos [...] A polícia já não controlava, nós tínhamos a polícia sindical. Já não havia ladrões. Nós mesmos fazíamos justiça, através do direito indígena, ou justiça comunitária [...] O poder estava nascendo, desde baixo, do chão ${ }^{7}$.

O evento que define a amplidão que tomaria o levante 296 popular de 2003 na região foi o ataque do exército, em 20 de setembro, aos habitantes de Warisata e Sorata, que assim como em outras partes do Altiplano, estavam mobilizados sob a liderança da CSUTCB comandada por Felipe Quispe. $\mathrm{O}$ resultado foi o assassinato de cinco pessoas, dentre elas uma criança.

No mês seguinte ao massacre de Warisata e Sorata, a revolta popular se intensificou com o anúncio do projeto do governo de exportar o gás para os Estados Unidos e México por um porto chileno. Dois fatores agravaram o quadro de descontentamento: a rejeição de grande parte da população à política de privatização realizada no anterior mandato presidencial de Sánchez de Lozada e o ressentimento histórico dos bolivianos por terem perdido o acesso ao mar para o Chile na Guerra do Pacífico (1879-1883). A cidade de El Alto, formada majoritariamente por migrantes camponeses

7 Entrevista com a autora realizada em La Paz, em dezembro de 2013. 
que se autoidentificam como indígenas, seria o principal palco da revolta de outubro - e seus habitantes, seus protagonistas e suas maiores vítimas.

O levante popular se espalhou pelo país. Setores sociais que desde 2000 vinham protagonizando mobilizações se uniram à luta contra o governo. Estradas foram bloqueadas por camponeses e greves gerais declaradas em importantes cidades. Em La Paz, algumas centenas de milhares de pessoas se reuniam. Nos últimos dias da insurgência popular, setores da classe média iniciaram uma greve de fome pedindo a renúncia do presidente boliviano.

No dia 17 de outubro de 2003, Sánchez de Lozada fugiu para os Estados Unidos com seus ministros mais próximos, dentre eles Sanchéz Berzaín, Ministro de Interior e um dos principais responsáveis pelo massacre cometido contra a população mobilizada, cujo resultado foi centenas de feridos e mais de sessenta pessoas mortas.

Com a posse do vice-presidente Carlos Mesa, a antiga ordem dava seus últimos suspiros. Apesar de oriundo de uma elite econômica e intelectual de La Paz, Mesa não era filiado a nenhum partido político. E, em função de seus embates com as elites do departamento de Santa Cruz, sua posse representou uma ruptura no bloco de poder. O MAS, segunda maior bancada no Parlamento, se tornou então fundamental para o novo governo. Pela primeira vez, o partido que havia se fortalecido com os votos daqueles que se levantavam contra a ordem vigente se tornou um dos alicerces do sistema político.

Sob forte pressão popular, Mesa convocou em 2004 um referendo sobre a concessão, exportação e utilização dos recursos do gás e sancionou a "Lei de Agrupações Cidadãs e Povos Indígenas”, acabando com o monopólio dos partidos políticos nas eleições. A pressão popular vinha, mormente, das organizações indígenas e camponesas que se mantinham mobilizadas e que, em setembro de 2004, formalizaram 
o "Pacto de Unidade", com objetivo criar uma plataforma comum de propostas para a convocação da Constituinte e para a nova Constituição. Os reflexos da marcha de 2002 apareceram em sua formação, cuja grande ausente foi a Cidob.

Em 2005, a crise política ganhou novo fôlego. Em janeiro, habitantes da cidade de El Alto se mobilizaram para expulsar a empresa Águas de Illimani. O movimento cocaleiro do Chapare, sob a liderança de Evo Morales, cujo partido já havia rompido com Mesa, anunciou a retomada dos bloqueios de estradas e o Conamaq realizou uma marcha até La Paz pela instauração da Assembleia Constituinte.

Sem o apoio do MAS ou da elite da Meia $\mathrm{Lua}^{8}$, a fragilidade do governo Mesa se tornou evidente. Em 2 de junho, $60 \%$ das estradas do país estavam bloqueadas (Gutiérrez Aguilar, 2008, p. 291). Diferentemente de seu antecessor, o governo de Mesa não respondeu à mobilização social com repressão e, no dia 6 de junho de 2005, 298 Carlos Mesa renunciou.

O processo de sucessão de Mesa envolveu uma grande disputa entre os que defendiam a ordem vigente e aqueles que buscavam subvertê-la. Manteve-se a mobilização social. Os insurgentes se opunham à possibilidade dos presidentes do Senado e da Câmara, os dois primeiros na linha de sucessão, assumirem o Poder Executivo, representando uma continuidade inaceitável da ordem política que vinha sendo questionada.

Ao impedir a posse daqueles representantes do Parlamento, a mobilização social provocou uma ruptura da ordem institucional, ampliando de forma definitiva o campo político institucional para a participação daqueles que, até então, tinham as ruas e estradas bolivianas como cenário privilegiado para sua atuação política.

\footnotetext{
8 A região denominada Meia Lua abarca os departamentos de Santa Cruz, Pando, Beni e Tarija.
} 


\section{Outsiders ocupam posições centrais no campo: a segunda fase da crise}

Como resultado da mobilização, Eduardo Rodríguez Veltzé, presidente da Suprema Corte de Justiça e terceiro na linha de sucessão, assumiu a presidência e convocou novas eleições para dezembro de 2005. Com 53,74\% dos votos, pela primeira vez desde a volta à democracia, um partido (MAS-IPSP) alcançou a maioria nas urnas e nenhum "pacto" no Parlamento foi necessário para que fossem empossados Evo Morales e Álvaro García Linera. Iniciava-se a segunda fase do ciclo de crise política. A partir de 2006, os papéis se inverteram: aqueles que haviam sido deslocados das posições centrais do campo buscaram a desestabilização institucional; enquanto os movimentos sociais, que haviam levado à desestabilização dos governos anteriores, colocavam-se como defensores da nova ordem.

Essas eleições marcaram uma reordenação do campo político institucional. Dos três principais partidos do período da democracia pactuada, apenas o Movimiento Nacionalista Revolucionario (MNR) apresentou candidato às eleições presidenciais. Desde a reforma aprovada durante o governo Mesa, as elites políticas e econômicas bolivianas haviam se organizado nas chamadas "agrupações cidadãs", como o Poder Democrático y Social (Podemos), que se tornaria a maior força de oposição e cujo principal representante era o ex-presidente Jorge Quiroga. Portanto, se por um lado os resultados das eleições presidenciais de 2005 indicam a perda de apoio popular aos partidos da aliança que levou Sánchez de Lozada à Presidência, por outro, os resultados eleitorais gerais daquele ano apontam a possibilidade de rearticulação de parte da elite política por meio das novas siglas. Essa estratégia foi relativamente bem-sucedida, pois embora o MAS tenha eleito a maior bancada na Câmara dos Deputados, a oposição alcançou a maioria 
dos votos no Senado, criando grandes entraves às iniciativas governamentais.

Não obstante as tentativas de bloqueio da oposição, o governo de Morales convocou eleições para deputados constituintes para julho de 2006. O governo enfrentava uma forte oposição do Senado e dos governadores da chamada Meia Lua, mas contava com o importante apoio das organizações indígenas e camponesas. A ausência de circunscrições especiais - demanda do movimento indígena que garantiria a representação direta de seus povos na Constituinte - tornava imperativa a cooperação dessas organizações com o MAS, que elegeu 53,7\% dos deputados constituintes, entre "orgânicos", representantes das organizações sociais, e "convidados”, intelectuais e profissionais urbanos (Garcés Velásquez, 2010, pp. 83-84).

À necessidade de articulação com o MAS e o governo acrescentava-se outra dificuldade, a construção de uma 300 proposta comum entre as organizações sociais do Pacto Unidade $^{9}$. Embora o Conamaq e a CSUTCB sejam, fundamentalmente, organizações que articulem camponeses indígenas do Altiplano boliviano, enquanto a CSUTCB nasce, em 1979, em torno de uma estrutura sindical, o Conamaq, formado quase vinte anos mais tarde, buscava a "reconstrução e consolidação dos povos indígenas originários, sob sua própria estrutura social, filosófica, política, econômica e cultural" (Consejo de Ayllus y Markas del Qullasuyu, 2008, p. 3). Essa diferença, aliada à disputa por influência nas comunidades do Altiplano, dificultava a aproximação das duas organizações durante os primeiros anos do ciclo crítico. No decurso do processo constituinte, o Conamaq formou com a Cidob o "bloco indígena". Essas organizações coincidiam em muitos pontos que lhes colocavam em dissenso com as

\footnotetext{
9 Para uma revisão do processo constituinte boliviano, cf. Garcés Velásquez (2013), Iamamoto (2011), Romero Bonifaz, Böhrt Irahola e Peñaranda Undurraga (2009) e Schavelzon (2010).
} 
organizações camponesas próximas ao MAS, dentre elas a CSUCTB, agora sob a liderança de Isaac Avalos, que participara da fundação do partido.

Não obstante as divergências a respeito de algumas propostas das organizações indígenas e camponesas para a nova constituição, em maio de 2007 o Pacto de Unidade apresentou uma proposta final consensual.

O tempo transcorrido entre a inauguração da Constituinte, em agosto de 2006, e a divulgação da última proposta do Pacto de Unidade foi marcado por uma intensa polarização política entre os constituintes próximos ao governo e à oposição e por alianças e acordos que teriam reflexos importantes na incorporação ou no rechaço de demandas das organizações do Pacto. O processo de crise política que se iniciara nos anos anteriores teve grande influência no desenrolar dos debates que ocorriam em Sucre, sede da Constituinte.

As disputas para a elaboração do regimento da Assembleia consumiram os primeiros meses de trabalho dos constituintes e, uma vez aprovados seu caráter originário e a regra dos dois terços para votação do novo texto, iniciou-se um trabalho de concertação por parte do MAS para alcançar o apoio necessário à aprovação da Constituição. Frente ao risco de que os acordos políticos excluíssem importantes demandas do movimento indígena, a Cidob organizou, em julho de 2007, a "VI Marcha Indígena pelas autonomias indígenas, terra e território e pelo estado plurinacional”. Esse episódio, bem como a mobilização da Asamblea del Pueblo Guarani (APG) para a inclusão de suas propostas sobre autonomia indígena, indicam os limites da abertura do campo político institucional representada pela Constituinte. Para muitos, o espaço da política continuava sendo as ruas e estradas do país.

Surgiram conflitos importantes entre algumas organizações do Pacto de Unidade e o MAS durante os trabalhos 
da Constituinte; e, durante a VI Marcha Indígena, evidenciaram-se as divisões internas do Pacto. De um lado, o Conamaq se mobilizou em apoio à marcha da Cidob; de outro, a CSUTCB e as demais organizações camponesas coincidiam com o governo nas críticas à mobilização.

Como estratégia de boicote ao trabalho dos constituintes, parte da oposição adotou como bandeira a defesa da cidade de Sucre como "capital plena" da Bolívia. Frente ao impasse no qual se encontrava a Constituinte e a possibilidade iminente de fracasso, em setembro, organizações camponesas se dirigiram a Sucre e iniciou-se um processo de diálogo em La Paz na busca dos dois terços dos votos necessários para aprovar a Constituição, com a presença de constituintes e líderes de diferentes partidos de oposição e sob a coordenação do vice-presidente García Linera (Schavelzon, 2010, pp. 235-241). Foram então criadas as Comissões de Diálogo e Consenso e a de Coordenação Política (Carrasco 302 Alurraide e Albó, 2008). Para Schavelzon, a tentativa de negociação com a oposição foi infrutífera, e ainda "debilitou as bases sociais do MAS, principalmente das organizações indígenas que viram cair por terra algumas de suas reivindicações" (2010, p. 270).

Apesar das divergências entre o MAS e as organizações indígenas durante os debates constituintes, estas dependiam fortemente do partido e de seus 137 constituintes para que fossem aprovadas suas demandas. Igualmente, a instabilidade política tornava o apoio das organizações indígenas fundamental para o MAS, pois sem a mobilização dos movimentos sociais, dificilmente o novo texto constitucional seria aprovado. Como resultado dessa aliança, em janeiro de 2007, movimentos sociais se reuniram com Evo Morales, García Linera, membros dos Poderes Executivo, Legislativo e da Constituinte, e criaram a Coordinadora Nacional por el Cambio (Conalcam), "uma espécie de 'estado maior' político cujo objetivo era apoiar o programa de reforma do governo 
Evo Morales"10. A mobilização de indígenas e camponeses garantiu a aprovação do texto constitucional em dezembro de 2007.

A crise política se acirraria a partir de 2008, colocando em risco a continuidade do "processo de mudança" liderado por Evo Morales. Naquele ano, foram ocupadas mais de 75 instituições estatais em cinco departamentos, houve dois cercos ao Poder Legislativo, referendos ilegais sobre estatutos autonômicos departamentais foram realizados, ocorreu o episódio conhecido como "massacre de Pando" e a constituição foi reescrita em grupos de trabalho (Miranda, 2012).

Nos primeiros meses de 2008, fracassaram as diferentes tentativas de diálogo entre o governo e a oposição para a convocação do referendo sobre nova Constituição. O Podemos liderava a oposição ao governo no Senado, enquanto os governadores dos departamentos da chamada Meia Lua orquestravam o enfraquecimento do governo por meio de referendos autonômicos departamentais. A disputa política ultrapassava as fronteiras do campo político institucional e, assim como durante o período de realização da Constituinte, tomava as ruas e estradas do país. Episódios de racismo e violência contra indígenas, camponeses, as sedes de suas organizações e de organizações não governamentais que os apoiavam foram recorrentes em 2008. Em um desses episódios, camponeses foram detidos em Sucre por militantes opositores ao governo e obrigados a despir-se parcialmente na praça principal, queimar suas bandeiras e se ajoelharem enquanto a multidão gritava "Sucre de pé! Evo de joelhos!"11.

Em dezembro de 2007, Morales enviara ao Congresso a Lei de Convocatória de um referendo revocatório - solução

\footnotetext{
${ }^{10}$ Disponível em: <https://bit.ly/2T0AdIX>. Acesso em: 15 abr. 2014.

11 Esses atos de violência foram transmitidos por canais de televisão, e algumas dessas imagens se encontram disponíveis em: <http://youtu.be/Y6Da5bO890I > Acesso em: 9 jul. 2016.
} 
encontrada para o impasse nas negociações políticas depois da Constituinte. A população devia decidir a respeito da continuidade do mandato de Evo Morales e García Linera e das autoridades executivas dos nove departamentos bolivianos. No dia 10 de agosto, $67 \%$ dos bolivianos votaram a favor da continuidade do governo - vencedor em 95 das 112 províncias do país ${ }^{12}$. O resultado representava um aumento considerável em relação aos votos obtidos em 2005 e indicava que, ainda que derrotado na Meia Lua, parte significativa da população desses departamentos apoiava Morales.

Embora importante, o resultado do referendo não levou a uma superação imediata da crise política. No dia 10 de setembro, o governo denunciou que um golpe de estado "atípico" estava sendo planejado por "grupos paramilitares fascistas e terroristas" dos governos e comitês cívicos da Meia Lua, além de anunciar a expulsão do embaixador estadunidense, acusado de financiar os grupos opositores. Diferente 304 do que ocorrera anos antes, o enfrentamento não se dava entre as forças repressivas governamentais e a população civil; agora, a disputa do campo político institucional se refletia nos embates nas ruas entre os que defendiam e se opunham ao proceso de cambio. As organizações dos setores subalternos superavam momentaneamente suas divergências, enquanto as rupturas no bloco opositor se evidenciavam. Enquanto parte da oposição buscava perpetuar a crise política, o governo punha em marcha uma estratégia de aproximação com o Podemos.

No dia 11 de setembro, o evento conhecido como "massacre de Pando" foi central na desarticulação da estratégia da oposição de desestabilização. Tratou-se de uma emboscada contra camponeses indígenas, que se dirigiam a um evento contra o governador do departamento do Pando, o opositor

\footnotetext{
12 Fonte: Vicepresidencia de la República: Unidad de Información para la Participación Ciudadana. "Resultados electorales, Referéndum Revocatorio 2008”.
} 
Leopoldo Fernandez. Estima-se que duas dezenas de manifestantes tenham sido assassinadas. Leopoldo Fernandez foi acusado de envolvimento, quando foram identificados funcionários de seu governo e veículos oficiais nos vídeos feitos no momento do ataque. Após a grande repercussão nacional e internacional do massacre, todos os governadores opositores aceitaram o acordo que o governador de Tarija negociava com o governo central (Peñaranda Undurraga, 2009).

Diferentemente do que ocorrera em 2003, quando os setores subalternos se levantaram para derrubar Sánchez de Lozada, a estratégia de mobilização da oposição foi ineficaz para interromper o mandato de Evo Morales. Este não apenas contava com uma legitimidade confirmada no referendo, como também mantinha a capacidade de mobilização de suas bases.

\section{"Una vez MAS porque así manda el pueblo"13: a volta à conjuntura ordinária}

A partir do diálogo com os governadores oposicionistas, duas mesas de negociação entre representantes da oposição e do governo foram organizadas em Cochabamba em setembro de 2008. Por dezessete dias, mudanças foram feitas no texto constitucional aprovado em Oruro.

Depois dos diálogos de Cochabamba, iniciou-se a negociação no Congresso. No dia 13 de outubro, a Conalcam organizou uma marcha pela convocação do referendo constituinte. A marcha começou em Oruro com cerca de sete mil pessoas, encabeçada por Evo Morales. Ao longo dos duzentos quilômetros percorridos, a mobilização cresceu e, chegando a La Paz em 20 de outubro, contava com cerca de cem mil manifestantes (Peñaranda Undurraga, 2009, p. 185). Depois de negociações com os partidos de oposição, o Congresso, cercado pelos manifestantes, aprovou

${ }^{13}$ Grafite em um muro da cidade de Sucre, jan. 2010. 
finalmente o acordo para a convocação do referendo constituinte, no dia 21 de outubro. O Congresso realizaria 144 modificações em 122 artigos da Constituição aprovada em Oruro (Garcés Velásquez, 2013, p. 35).

No dia 25 de janeiro de 2009, 61,43\% dos bolivianos votaram pela aprovação da nova Constituição. Naquele dia, Evo Morales declarava: "aqui acabou o colonialismo interno e externo, acabou o Estado colonial, aqui acabou o neoliberalismo" ${ }^{14}$. Novas eleições foram convocadas e, em dezembro daquele ano, Morales foi reeleito com 64,22\% dos votos e o MAS alcançou a maioria nas duas casas da Assembleia Legislativa Plurinacional.

Os debates que precederam as eleições de 2009, para a elaboração da Lei de Regime Eleitoral Transitório, refletiram tensões no bloco de setores subalternos que apareciam já durante o primeiro ciclo de crise política (2000-2005) e no processo de elaboração e modificação do texto consti306 tucional. O ponto central que opunha o governo às organizações indígenas, notadamente a Cidob e o Conamaq, era sobre o número de cadeiras da Assembleia Legislativa destinadas a representantes indígenas, eleitos por formas próprias, que ficaram reduzidas a sete, um número bastante inferior àquele demandado pela Cidob e pelo Conamaq (Garcés Velásquez, 2013, pp. 65-66). Apesar das divergências entre as organizações indígenas e o governo, nas eleições de 2009, aquelas apoiaram mais uma vez os candidatos do MAS.

Os resultados eleitorais de 2009 e 2010 marcaram o fortalecimento do MAS no comando do governo nacional e do Legislativo e uma maior presença nos departamentos ${ }^{15}$.

\footnotetext{
14 Disponível em: <https://bit.ly/2Pm6dbY>. Acesso em: 9 jul. 2016.

15 Em abril de 2010, foram eleitos os governadores departamentais, os prefeitos (alcaldes) e os representantes das assembleias legislativas departamentais. $\mathrm{Na}$ eleição para governadores, o MAS ganhou em Chuquisaca, La Paz, Pando, Cochabamba, Oruro e Potosí; perdendo apenas nos departamentos de Santa Cruz, Tarija e Beni. Disponível em: <https://bit.ly/2qEevNE>. Acesso em: 14 jul. 2016.
} 
A promulgação da nova Constituição foi um passo fundamental, mas não definitivo, na construção do novo Estado boliviano. As novas regras indicavam que outra lógica estatal deveria ser criada, mas este processo ocorreria a partir de instituições e lógicas que haviam sobrevivido ao período crítico. Tais limites levaram a um importante distanciamento entre as organizações indígenas e o governo central.

Foi durante os debates em torno da elaboração da Lei Marco de Autonomias que apareceram os primeiros indícios de que tais afastamentos levariam a uma ruptura. Em um contexto de maior estabilidade institucional, foi promulgada em 2010 a Lei Marco de Autonomias e Descentralização Andrés Ibañez, acusada por muitos atores de criar novos "cadeados" à implantação da autonomia indígena ${ }^{16}$. Durante a elaboração da lei, a Cidob organizou, com o apoio de Conamaq, entre junho e julho de 2010, a VII Marcha Indígena, reivindicando a incorporação de suas propostas ao projeto de lei.

Após a ruptura nos diálogos com o governo, a VII Marcha indígena partiu de Trinidad em 21 de junho de 2010 para La Paz, com aproximadamente quatrocentos integrantes. Com o passar dos dias, novos atores, como o Conamaq, declararam seu apoio à marcha da Cidob.

O Ministro de Autonomias foi denunciado pelos coordenadores da marcha por não buscar o diálogo com as organizações indígenas e por criar falsas acusações com o intuito de deslegitimar a mobilização. Base de apoio do governo, os cocaleiros se posicionaram contra a marcha. Finalmente, dois senadores do MAS negociaram com representantes dos indígenas mobilizados e algumas de suas demandas foram incluídas na Lei Marco de Autonomias.

16 Dentre os "cadeados" denunciados estariam a exigência de um limite populacional, o respeito às fronteiras departamentais e a necessidade de um "certificado de ancestralidade". 
Dentre as reivindicações da VII Marcha Indígena liderada pela Cidob, estava a garantia do direito constitucional à consulta prévia aos povos e nações indígenas, quando medidas legislativas ou administrativas possam afetá-los. E, em 2011, essa discussão se tornou central no debate político quando organizações do Território Indígena e Parque Nacional Isiboro Sécure (Tipnis) e a Cidob organizaram a "VIII Marcha Indígena pela Defesa do Tipnis", questionando o trajeto da estrada que cruzaria o território do Tipnis ${ }^{17}$. A maior parte do custo da obra seria financiada pelo Banco Nacional de Desenvolvimento Econômico e Social brasileiro (BNDES), levantando dúvidas a respeito de seu principal beneficiário. A marcha partiu de Trinidad, no departamento do Beni, em direção a La Paz em 15 de agosto de 2011, com aproximadamente setecentos integrantes. Houve hostilidade por parte dos camponeses que apoiavam a construção da estrada. Uma das queixas dos indígenas era o fato da rota 308 escolhida para a estrada facilitar a ocupação de terras dentro do Tipnis por cocaleiros.

A repressão do governo à marcha evidenciou a ruptura entre o MAS e as organizações indígenas. Ademais, o conflito do Tipnis deixou patente a separação entre organizações camponesas e indígenas e as divisões no interior das últimas.

Em 2012, a divisão no interior da Cidob e do Conamaq era incontestável. Em 10 de julho realizou-se uma Grande Assembleia dos Povos Indígenas (Gampi) das Terras Baixas, para a formação de um novo diretório nacional para a Cidob. Adolfo Chávez, eleito presidente da organização em 2010 para um período de quatro anos, teve seu mandato desconhecido e Melva Hurtado, autoridade histórica da organização, foi eleita presidenta da Cidob. Chávez, uma

\footnotetext{
17 Para uma reconstrução detalhada da VIII Marcha, cf. Fundación Tierra (2011a, 2011b).
} 
das principais lideranças das VII e VIII Marchas Indígenas, apoiado por parte da Cidob, não reconheceu a nova eleição e acusou o governo do MAS de fomentar a divisão da organização. Formaram-se então duas Cidob: uma mais próxima ao governo - que em outubro de 2012, “coroou” Evo Morales como "cacique geral" - e outra, sob o comando de Chávez.

O governo do MAS foi acusado igualmente de fomentar a divisão do Conamaq que, no final de 2012, representava apenas treze dos seus dezesseis suyus. O diretório eleito em dezembro de 2011 acusava as autoridades anteriores de serem muito próximas ao MAS. Com efeito, uma das estratégias do Conamaq nos primeiros anos do governo de Morales era a ocupação de espaços dentro da estrutura estatal, com a incorporação de seus assessores em diferentes ministérios.

Em dezembro de 2013, a disputa no interior do Conamaq culminou com enfrentamentos diante da sede da organização em La Paz. É bastante representativo das mudanças ocorridas no campo político boliviano nos anos anteriores o fato de o governo MAS ser então acusado de impedir o acesso dos representantes da organização à casa que ele próprio havia doado ao Conamaq cinco anos antes.

\section{Considerações finais}

Organizações camponesas e indígenas foram criadas na Bolívia a partir da transição para o regime democrático. Entre os anos de 2000 e 2005, esses atores foram fundamentais na contestação da ordem política vigente, que excluía sua participação. Foi por meio da mobilização de setores subalternos que as fronteiras do campo político institucional boliviano foram rompidas, durante a primeira fase (20002005) de um longo ciclo de crises políticas.

Na segunda fase do ciclo crítico (2006-2008), novos atores passaram a ocupar posições centrais do campo, com a posse de Evo Morales, de um grande número de deputados do MAS e a realização da Assembleia Constituinte. Nesse 
período, as tentativas de desestabilização política por parte daqueles que haviam sido deslocados do centro do campo político institucional tornavam ainda mais importantes as alianças entre as organizações indígenas e camponesas e entre essas e o MAS.

Se 2008 foi marcado por uma forte crise política, parece também ter sido o ano da superação do ciclo iniciado em 2000, e que perdurara após a primeira eleição de Evo Morales, ainda que com características distintas. O ciclo crítico termina quando finalmente o governo do MAS é aceito pela oposição institucional. Com efeito, essa "aceitação" foi resultado da atuação de setores subalternos que se mantiveram mobilizados ao longo da segunda fase do ciclo, do crescente enfraquecimento e perda de legitimidade da oposição, e da vitória do governo no referendo revogatório de mandato.

O fato de o texto constitucional ter sido editado em acordos com a oposição parlamentar, com pouca ou 310 nenhuma participação das organizações camponesas e indígenas - que em grande medida garantiram a realização da Assembleia Constituinte - indica que o campo político institucional voltava a funcionar com suas lógicas sociais específicas. O campo volta a captar o cálculo dos atores, suas regras voltam a ser valorizadas (Dobry, 1992). O processo de reorganização das fronteiras do campo se tornou patente durante os debates em torno da Lei de Autonomias e no conflito do Tipnis. O governo recorreu então a estratégias de deslegitimação das organizações indígenas; as mesmas às quais apelavam os governos da "democracia pactuada" em momentos de mobilização social.

A reconstrução das "jogadas dos atores" (Dobry, 1992) - principalmente dos governos centrais e das três organizações sociais analisadas - durante o ciclo de crises políticas permite entender a reconfiguração das fronteiras do campo político institucional uma vez superadas as crises. Se durante as crises políticas - únicos momentos possíveis de encontro 
da diversidade boliviana, expressa nos diferentes tempos, rostos, línguas, latitudes e modos de produção (Zavaleta Mercado, 1983) - já apareciam as dificuldades de articulação entre as diferentes organizações indígenas e camponesas e entre essas e o governo do MAS; que essas diferenças se fortaleçam em "conjunturas ordinárias" não surpreende. A exclusão de determinados atores (como Felipe Quispe) e organizações (como a Cidob e o Conamaq) pode então ser lida à luz dos inúmeros desencontros anteriores.

É incontestável que a expansão do campo político institucional tenha incluído atores que antes participavam da política em espaços fora desse campo. A presença de vários homens e mulheres indígenas na Assembleia Legislativa Plurinacional é uma prova. Contudo, esse movimento se confunde com o crescimento do MAS, uma vez que é possível observar uma exclusão do campo daqueles atores indígenas dissonantes do discurso do partido. Dessa forma, com a superação da crise, as fronteiras do campo político institucional foram redefinidas, deixando de fora muitos daqueles que haviam participado ativamente de sua abertura durante o ciclo de crises políticas dos anos anteriores.

\section{Rafaela N. Pannain}

É pesquisadora de pós-doutorado do Centro Brasileiro para Análise e Planejamento (Cebrap) e membro do grupo de trabalho Clacso "Pueblos indígenas y procesos autonómicos”. Mestre em Ciência Política/Relações Internacionais pela Université Paris 1 Sorbonne (2008) e doutora em Sociologia pela Universidade de São Paulo (2014).

\section{Bibliografia}

CALDERON GUTIÉRREZ, Fernando; GAMARRA, Eduardo. 2004. Crisis y reforma de los partidos en Bolivia. La Paz: PNUD.

CARRASCO ALURRAIDE, Inés Valeria; ALBÓ, Xavier. 2008. Cronología de la Asamblea Constituyente. Tinkazos, v. 11, n. 23-24, pp. 101-125. 
CHÁVEZ, Patricia; MOKRANI, Dunia. 2007. Los movimientos sociales en la Asamblea Constituyente: hacia la reconfiguración de la política. OSAL: Observatorio Social de América Latina, v. 8, n. 22, pp. 107-117. CONSEJO DE AYLLUS Y MARKAS DEL QULLASUYU. 2008. Plan estrategico 2008-2013: Conamaq. La Paz: Coincabol.

DOBRY, Michel. 1992. Sociologie des crises politiques : la dynamique des mobilisations multisectorielles. 2. ed. Paris: Presses de la Fondation Nationale des Sciences Politiques.

DUNKERLEY, James. 2007. Evo Morales, the "Two Bolivias" and the Third Bolivian Revolution. Journal of Latin American Studies, v. 39, n. 1, pp. 133-166.

FUNDACIÓN TIERRA. 2011a. Dos meses de marcha en defensa del Tipnis. La Paz: Fundación Tierra. Coleção Nuestra Tierra, n. 7. . 2011b. Marcha indígena por el Tipnis: la lucha en defensa de los territorios. La Paz: Fundación Tierra.

GARCÉS VELÁSQUEZ, Fernando. 2010. El Pacto de Unidad y el proceso de construcción de una propuesta de constitución política del Estado: sistematización de la experiencia. La Paz: Preview.

. 2013. Los indígenas y su Estado (pluri)nacional: una mirada al proceso 312 UMSS.

GARCÍA LINERA, Álvaro. 2008a. La potencia plebeya: acción colectiva e identidades indígenas, obreras y populares en Bolivia. Buenos Aires: Prometeo; Clacso. (coord.). 2008b. Sociología de los movimientos sociales en Bolivia: estructuras de movilización, repertorios culturales y acción política. 3. ed. La Paz: Plural.

GUTIÉRREZ AGUILAR, Raquel. 2008. Los ritmos del Pachakuti: movilización y levantamiento indigena-popular en Bolivia. Buenos Aires: Tinta Limón. HYLTON, Forrest; THOMSON, Sinclair. 2005. The chequered rainbow. New Left Review, v. 35, n. 1, pp. 41-64.

IAMAMOTO, Sue Angélica Serra. 2011. O nacionalismo boliviano em tempos de plurinacionalidade: Revoltas antineoliberais e constituinte (2000-2009). 2011. 175 f. Dissertação de Mestrado em Ciência Política. São Paulo: USP.

MAMANI RAMÍREZ, Pablo. 2007. Bolivia antes de Evo Morales: fractura del Estado colonial: poder de los microgobiernos indígenas. Bolivian Studies Journal, v. 7, n. 1, pp. 1-26.

MAYORGA, Fernando. 2009. El gobierno de Evo Morales: nacionalismo e indigenismo en tiempos de cambio. In: TANAKA, Martín (comp.). 
La nueva coyuntura critica en los países andinos. Lima: IEP; IDEA Internacional, pp. 125-151.

MIRANDA, Boris. 2012. La mañana después de la guerra. La Paz: El Cuervo.

PANNAIN, Rafaela Nunes. 2014. A crise do Estado boliviano e a autonomia indígena. 2014. 300 f. Tese de Doutorado em Sociologia. São Paulo: USP.

PEÑARANDA UNDURRAGA, Raúl. 2009. Crónica del proceso constituyente. In: ROMERO BONIFAZ, Carlos; BÖHRT IRAHOLA, Carlos; PEÑARANDA UNDURRAGA, Raúl. Del conflicto al diálogo: memorias del acuerdo constitucional. La Paz: fBDM; FES-ILDIS, pp. 107-201.

RIVERA CUSICANQUI, Silvia. 1983. Luchas campesinas contemporáneas en Bolivia: el movimiento katarista: 1970-1980. In: ZAVALETA MERCADO, René (comp.). Bolivia hoy. Ciudad del México, DF: Siglo Veintiuno, pp. 129-168.

ROMERO BONIFAZ, Carlos. 2005. El proceso constituyente boliviano. Santa Cruz de la Sierra: Cejis.

ROMERO BONIFAZ, Carlos; BÖHRT IRAHOLA, Carlos; PEÑARANDA UNDURRAGA, Raúl. 2009. Del conflicto al diálogo: memorias del acuerdo constitucional. La Paz: fBDM, FES-ILDIS.

SCHAVELZON, Salvador. 2010. A Assembleia Constituinte da Bolivia: etnografia do nascimento de um Estado plurinacional. 2010. 590 f. Tese de Doutorado em Antropologia Social. Rio de Janeiro: UFRJ; Museu Nacional.

STEFANONI, Pablo. 2002. El nacionalismo indígena como identidad política: la emergencia del MAS-IPSP (1995-2003). In: CONSEJO LATINOAMERICANO DE CIENCIAS SOCIALES (ed.). Informe final del concurso: movimientos sociales y nuevos conflictos en América Latina y el Caribe. Buenos Aires: Clacso, pp. 1-49.

TAPIA, Luis. 2005. La cuarta derrota del neoliberalismo en Bolivia. OSAL: Observatorio Social de América Latina, v. 6, n. 17, pp. 153-158. 2007. Una reflexión sobre la idea de Estado plurinacional, OSAL: Observatorio Social de América Latina, v. 8, n. 22, pp. 47-63. 2010. El estado en condiciones de abigarramiento. In: GARCÍA LINERA, Álvaro et al. (org.). El Estado: campo de lucha. La Paz: Clacso; Comuna; Muela del Diablo, pp. 97-128.

URQUIDI, Vivian Grace Fernandez Davila. 2007. Movimento cocaleiro na Bolívia. São Paulo: Hucitec.

ZAVALETA MERCADO, René. 1983. Las masas en noviembre. In: (org.). Bolivia hoy. Ciudad del México, DF: Siglo Veintiuno, pp. 11-59. 


\section{A RECONFIGURAÇÃO DA POLÍTICA BOLIVIANA: RECONSTITUIÇÃO DE UM CICLO DE CRISES}

\section{RAFAELA N. PANNAIN}

Resumo: Este artigo apresenta uma reconstituição do último ciclo de crises políticas vividas pela Bolívia (2000-2008), a partir, notadamente, da ação de três organizações sociais: a Confederación Sindical Única de Trabajadores Campesinos de Bolivia (CSUTCB), a Confederación de los Pueblos Indígenas de Bolivia (Cidob) e o Consejo de Ayllus y Markas del Qullasuyu (Conamaq). Na primeira fase do ciclo, a forte mobilização social rompeu com as fronteiras do campo político institucional; na segunda, a crise política adquiriu novas características à medida que atores deslocados do controle do poder político nacional buscaram a desestabilização institucional. Com a superação da crise e o retorno à "conjuntura ordinária”, as fronteiras do campo foram redefinidas, excluindo parte daqueles atores indígenas que haviam atuado na construção de um novo Estado.

Palavras-chave: Crise política; Bolívia; Organizações indígenas; Evo Morales.

\section{RECONFIGURATION OF BOLIVIAN POLITICS: RECONSTITUTION OF A CYCLE OF CRISES}

Abstract: This article presents a reconstitution of the last cycle of political crisis in Bolivia (2000-2008), following mainly the action of three social organizations: the Confederación Sindical Única de Trabajadores Campesinos de Bolivia (CSUTCB), the Confederación de los Pueblos Indígenas de Bolivia (Cidob) and the Consejo de Ayllus y Markas del Qullasuyu (Conamaq). During the first critical years, the strong social mobilization shattered the borders of the institutional political field; later on, the political crisis changed as those who had been replaced in the control 
of national political power tried to disrupt the institutional power. After the political crisis was overcome, the boundaries of the field were restructured, excluding some of the indigenous persons who had acted on the construction of the new State.

Keywords: Political crisis; Bolivia; Indigenous organizations; Evo Morales.

Recebido: 25/07/18 Aprovado: 01/11/18 